\title{
1
}

\section{The Global Development, Diffusion, and Transformation of Education Systems: Transnational Isomorphism and 'Cultural Spheres'}

\section{Michael Windzio and Kerstin Martens}

\section{Introduction $^{1}$}

The purpose of the research presented in this volume is a wide-ranging analysis and explanation of the dynamics of emergence, diffusion, and change in relation to state education systems. Countries learn from each other due to traveling experts and the exchange of personnel. This is an essential characteristic of modernity, despite the tradition having a long history dating back to Medieval and Ancient times (Weymann 2014). In many respects, globalization and corresponding mobility have gained

\footnotetext{
${ }^{1}$ This chapter is a product of the research conducted in the Collaborative Research Center, "Global Dynamics of Social Policy" at the University of Bremen. The center is funded by the Deutsche Forschungsgemeinschaft (DFG, German Research Foundation)—project number 374666841 SFB 1342.
}

M. Windzio $(\square)$

SOCIUM and Collaborative Research Centre 1342 "Global Dynamics of Social Policy", University of Bremen, Bremen, Germany e-mail: mwindzio@uni-bremen.de 
considerable momentum since World War II (WWII) and sped up even more from the 1990s onward and after the end of the Cold War. This was not only due to new techniques of global communication and the available traveling infrastructure of the time, but rather it was also attributed to the increased importance of transnational interlinkages, multinational companies, and international organizations (IOs). Today, economic transactions have become progressively organized at a global scale but also political claims for human and social rights, as well as ideas about the objectives of education and education policies are distributed globally (Martens et al. 2014). In this volume, we identify the global pathways to education and investigate the causes of change of education systems from a global and historical perspective. We argue that the emergence and development of education systems can be traced back not only to inherent national factors but also to the international diffusion of ideas.

In essence, we investigate empirically how the global diffusion of Western-rational educational content and organizational forms proceeds, as expected by neo-institutionalist theory (Meyer et al. 1997) and whether culturally specific developmental pathways dominate in different parts of the world. Taken together, the chapters in this book aim at three different goals: Firstly, by gathering event and network data, the global horizontal diffusion of state-organized education systems is investigated for most countries in the world. In particular, we analyze the timing when state regulation of compulsory schooling and state financing of the education system were introduced. Secondly, we map the extent of vertical interdependencies between IOs active in the field of education. IOs develop and spread educational models and standards globally, and these reach member states as well as non-member countries. By means of qualitative documentary analyses, expert interviews, and topic modeling, we investigate the educational models propagated by selected IOs. Thirdly, historical

\section{K. Martens}

Institute for Intercultural and International Studies (InIIS) and Collaborative Research Centre 1342 “Global Dynamics of Social Policy”, University of Bremen, Bremen, Germany e-mail: martensk@uni-bremen.de 
macro-data is employed to identify the national and international factors which determine the introduction of and changes to education policy. It is postulated that in addition to a country's affiliation with consolidated regional and cultural networks, state-internal demands on education policy originating from other subsystems or policy fields are also significant for both the development and the transformation of educational statehood.

In the following section, we present a short overview of existing research in this field concerning our work. We then present the theoretical framework of our study, which focuses on the tension between the global institutionalization of Western rationality, on the one hand, and culturally specific rationales for the development of education, on the other hand. In essence, we argue that the interplay between horizontal and vertical interdependencies, as well as the moderating effects of national factors are still neglected research topics when it comes to the global development of education policy. The final section provides an outline of the book structure and our empirical implementation.

\section{Recapturing Research: Education Policy from a Global Perspective}

In the context of the advancing globalization of economies and transnational interdependencies arising through migration (Castles et al. 2014), education systems are expected to maintain national economic competitiveness in world markets while also preparing their graduates for global competition in labor markets. Education is viewed as a 'social investment' as it creates an economically productive population stratum that can finance social policy while offering protection against the risks of unemployment and poverty (Allmendinger and Leibfried 2003). Furthermore, state education systems fulfill the fundamental task of socializing the population and inculcating literacy, thus producing wellintegrated citizens (Nagel et al. 2010). Obviously, education is fundamental to T. H. Marshall's (1964 [1949]) "social citizenship". Consequently, state education systems are required to fulfill disparate 
demands (Windzio 2013) and are simultaneously influenced by national and international factors. A country's economic performance, for example, influences the configuration of its national education system (Hanushek et al. 2013). Similarly, party-political ideologies (Ansell 2010) or religious actors (Yakhyaeva 2013; Brock and Alexiadou 2013)—especially in Central Asia and some African countries-influence the objectives of education policy. As we know from existing research, the performance of education systems also varies considerably between countries and their institutional structures (Teltemann and Windzio 2011, 2019; Hanushek et al. 2013).

Since the late 1970s, the emergence, development, and global diffusion of different types of education systems have become an object of inquiry in the social sciences (overviews include: Gift and Webbel 2014; Busemeyer and Trampusch 2011; Jakobi et al. 2010). In the context of mass inclusion, studies focus primarily on the structural changes to national education systems, the changing syllabuses for general education (Meyer 1977; Benavot and Riddle 1988), and expenditure on the public as well as private education (Wolf and Zohlnhöfer 2009). The influence of international organizations on national education policy has also been outlined, although mainly in case studies on single IOs (examples include Ydesen 2019; Finnemore 1993 and the contributions in Martens et al. 2007, Grek 2010; Mundy 2007; Bieber and Martens 2011). Various studies, for example, have demonstrated the influence of the World Bank's (WB) funds on the development and direction of national education systems in low-income countries (e.g. Mundy and Verger 2015). In contrast, international interdependencies that have grown historically over a long period of time, such as colonialism, may be significant, for example, for African countries south of the Sahara (Brock and Alexiadou 2013) and have received relatively little attention in studies on global diffusion of education.

Inspired by the neo-institutionalist thesis of the diffusion of modern forms of rationality and social order, some studies postulate that an analogous expansion of modern state educational establishments has occurred and that there is a long-term tendency toward global convergence in education systems (Meyer et al. 1992; Jakobi and Teltemann 2011). From the neo-institutionalist perspective, cultural patterns, rationality criteria, and institutional structures that emerged in the Occident are spreading 
globally, partly due to the influence of IOs and nongovernmental organizations (NGOs) (McNeely and Cha 1994; Finnemore 1993). Furthermore, formal organizations and bureaucratically organized states constitute an ideal basis for instrumental action and are likely to spread globally due to their efficiency (Meyer et al. 1997, 153). However, the global diffusion of guiding models for state organization can only occur if the structural precondition of suitable channels for relationships and exchanges is satisfied. Thus, it is not surprising that recent studies in international relations increasingly employ methods of network analysis that can, among other things, describe the linkages between countries constituted by membership in IOs or through migration (Maoz 2011; Vögtle and Windzio 2019; Windzio 2018; Windzio et al. 2019).

New approaches in diffusion research emphasize that peculiarities in network topologies, such as communities that are highly integrated internally yet isolated externally, can strongly influence the spread of innovation (Centola 2015). Cross-national relationships of exchange can be highly consolidated regionally, as seen in world regions or cultural spheres such as those formed among Islamic, Western, Central European, or West Asian countries. In contrast to Huntington's tension-laden "fault lines" (Huntington 1993, 29), cultures can merge or overlap margins while still pursuing their own developmental paths at the core (Knöbl 2007). In the field of education, the geographical and cultural dimensions of cultural spheres have not been sufficiently investigated as a potential moderator of isomorphism.

We assume that cultural spheres or regionally consolidated network topologies structure the diffusion of state education systems. In taking this approach, neo-institutionalism remains open to the diversity of cultures, and to resistance to the diffusion of Western rationalism (Finnemore 1996, 342). Possible consequences of heterogeneity are creative responses, recreations, and enrichments of the rationalist framework (Knöbl 2007, 43). However, previous work on the diffusion of state education has often been restricted to the realm of the Organisation for Economic Co-operation and Development (OECD) 'world' (Meyer et al. 1992). Only recently, have scholars extended their perspectives to include more countries in the world than just the industrialized North (Barro and Lee 2013). Only with such a global perspective can regionally and culturally specific pathways to education and education policy be detected. 
Thus, the existing literature indicates that further research is required, for example, on the influence of horizontal interdependencies across countries and vertical interdependencies through IOs in the field of education. If education makes a significant contribution to the transmission of culture, the differentiation in various cultural spheres should influence the emergence and spread of national state education systems, as well as any changes in these systems. In addition, the kind and the extent to which IOs develop and spread ideas about education and education policy on a global scale has not been examined sufficiently. Also, the question remains if specific influences of IOs in individual cultural spheres can be established that possibly work against a global trend to isomorphism. Previous studies have mainly focused on the expansion of the nation-state as the starting point for universal education (e.g. Boli et al. 1985; Ansell and Lindvall 2013). The influence of IOs as providers of ideas and impulses for the developmental dynamics of education policy has largely been overlooked (one exception is Verger 2012). We expect that not only functional and transnational influences can be identified in globalization processes. In addition, we expect effects of regional-cultural consolidation in diffusion networks, ranging from identity-political countermovements to a possible global trend toward isomorphism.

In response to the previously mentioned desiderata, this volume seeks to build and expand upon the findings from previous research in several respects. In light of its theoretical perspective, our book is able to participate in macro-sociological debates on the reach and form of the diffusion of Western-modern rationality and forms of order (Krücken 2005). When appropriate, it is also able to trace empirically the significance of self-contained regional and cultural paths (Eisenstadt 1986; Knöbl 2007). We also relate to constructivist studies in international relations as we examine the potential of IOs to develop and spread ideas, values, and norms. By combining these fields and applying a wide set of methodological tools in this study, we align our research to current studies in global education governance (Karseth et al. 2021). In the field of education policy, it is crucial to analyze these specific paths because education is inextricably linked with the maintenance and reproduction of culture, history, religion, and identity. The decisive factors in the evolution, diffusion, and transformation of education policy will be further described in our theoretical framework, which follows in the next section. 


\section{Theoretical Framework: Transnational Isomorphism versus Cultural Spheres in Education}

Long-term trends of globalization result from macro- as well as microprocesses. First and foremost, globalization implies that nation-states transfer political authority and governance capacities to international or supranational organizations. However, globalization is also driven from 'below' by transnational networks of politicians, experts, or migrants (Castles et al. 2014). From a sociological perspective, the content of global diffusion via transnational networks includes monetary transfer but also institutions, practices, routines, and taken-for-granted knowledge. In this sense, globalization implies a level of cultural convergence. The globalization debate is at the core of early sociological theory, when Max Weber (1972) described the evolution and diffusion of rationalization, beginning with Protestant sects in Europe and America in the seventeenth century. Interestingly, just a few years after the City of Boston was founded in 1630, the Massachusetts Bay Company enacted a law to finance primary schools with local taxes for the purpose of religious education (Brock and Alexiadou 2013). Although limited to a selective group, this early precursor of publicly financed education was invented in the colony. Much later, with the Education Act of 1870, the British government turned compulsory education into a public matter.

The theoretical debate on the global diffusion of occidental rationalism has prominently lasted until today, where it is represented by sociological neo-institutionalism (Meyer et al. 1997). We identify two broad theoretical strands in this debate. Proponents of the isomorphism thesis expect a global diffusion of Western rationalization that also affects education systems. Organizational forms and curricular content might become increasingly similar across the world in the long run. The cultural spheres concept, in contrast, focuses on different cultural clusters defined by religious characteristics, gender role orientations, language groups, civil rights, and rule of law. If two countries share a cultural characteristic, they establish a link in a network. The more cultural characteristics they share, the stronger they are tied to each other. This valued cultural 
network is a fuzzy set typology of world cultures. It is the pipe structure through which education policies can spread around the globe. Its topology can moderate or also block the diffusion process (Centola 2015). The network comprises different pathways, even though the assumed general trend toward isomorphism, for example, in terms of compulsory schooling, is rather uncontroversial.

\section{Transnational Isomorphism}

The modern wave of globalization since the 1950s resulted from structural conditions without parallel in world history. Scholars in the social sciences observed the diffusion of organizational forms and knowledge at an unprecedented scale. These observations led to the theoretical concept of isomorphism (Meyer et al. 1997). Indeed, if some bureaucratic organizational forms are more efficient than others (Weber 1972), and if at the same time international organizations require certain standards of accountability from their member states, it is far from implausible to expect that these efficient forms achieve evolutionary success at a global scale. Nation-states are keen to adopt bureaucratic organizational forms as instruments for exerting authority in a way that guarantees predictable obedience and stability, without just relying on coercion and brutal force. In this regard, education has been crucial in the process of state formation (Green 2013).

Efficient and modern organizational forms are attractive in the fields of legislation, administration, policing, and law enforcement. Yet, since Bismarck introduced the social insurance system, most European policymakers are aware that social policy essentially contributes to the legitimacy of authority and to political stability in market-based economies. Contingencies in economic development pose serious risks to the labor force, particularly to the most vulnerable segments, for example, to the low-qualified working poor. As a result, social upheaval and political instability become more likely. Alternatively, neoclassical economists limit their concepts of social policy to the development of the individual (Allais 2012). Skill formation, labor market qualification, and professionalization-all of which require a sufficient amount of general 
education - are supposed to reduce individual levels of vulnerability and increase economic productivity. Moreover, an increase in productivity increases the amount of the domestic budget to be redistributed through social policy programs. In this regard, education policy is either a specific form of social policy or a functional equivalent.

Social policy can be regarded as a crucial aspect of the 'one best way to organize' (Cummings et al. 2017) from the modern, democratic state's perspective. In this view, generating legitimacy by institutionalizing social policy is an effective approach to smooth government. At the very least, the normative expectation of rational and efficient authority is institutionalized in a state's environment. In addition, social policy is evaluated in global mass communication and by international organizations with respect to social justice and moral standards. If social policies are not in line with the institutionalized normative expectations, there will be considerable normative pressure to conform to these expectations (Meyer et al. 1997).

Bureaucratic authority depends on a minimum level of basic education among its inhabitants, who need a certain level of literacy to read and follow written instructions as well as legal regulations (Weymann 2014). Adopting efficient education policy, however, should also increase the employability of the labor force and thereby increase productivity, tax revenues, and the contributions to the social security system. Again, education organizations are expected to be accountable and reliable bureaucracies with a curriculum that should not be in conflict with the ideologies needed to provide belief in the legitimacy (Weber 1972) or the 'legitimacy myths' (Meyer et al. 1997, 160) of the institutionalized order. Liberal democracies and legal states that guarantee personal freedom to the individual require citizens who believe in the value of the respective institutions. Regarding these outcomes and the benefits of education policy, can we expect a global isomorphism in the forms and content of education systems? Perhaps it can be expected, even though education policy has a particular feature: It closely relates to the intergenerational reproduction of a society's culture and their collective identities, for example, ethnic, religious, or national, which all seem to have gained importance during the last three decades. 


\section{Cultural Spheres}

Education strongly affects the intergenerational transmission of knowledge, national traditions, identities, and culture more so than other kinds of social policy, including family policy. Relational sociology agrees with the view that a particular culture is not an 'essence'; rather than being a stable entity, culture is embedded in a network of socially constructed elements and gains its identity from relations between these elements. For instance, the valuation of personal autonomy in one culture acquires its significance in relation to other cultures, just as the relationship with other socially constructed elements gives a culture its meaning. Rather than having clearly specified boundaries, elements of cultures are related to each other like fuzzy set clusters, as we know from social network analysis (Emirbayer 1997, 299; Emirbayer and Goodwin 1994).

Highlighting the challenges of global cultural differences instead of their benefits became increasingly controversial from the mid-1990s when Huntington (1996) responded to Fukuyama's optimistic view on the end of history (Fukuyama 1992). Huntington argued that future global conflicts would occur at religious-cultural 'fault lines' separating different civilizations from each other (Huntington 1996). His work has been accused of paving the way for anti-multicultural backlash because it focuses on cultural confrontation rather than on benefits due to diversity (Perry 2002). Yet, recent studies in evolutionary anthropology and psychology have emphasized the general importance of culture. Culture played a crucial role in human evolution and even today we are still a 'cultural species' (Henrich 2016). For example, early humans' niche construction was based on the social transmission of knowledge, for example, on hunting, toolmaking, and food preparation, which even affected humans' genetic disposition during evolution. Selective genetic adaptation created the human species whose members are incapable of existing as isolated individuals without an appropriate social and cultural environment (Henrich 2016). Human's gene-culture coevolution created us as 'norm internalizers', but this came at the cost of a tendency toward keeping social distance between cultural groups. Norm compliance and cooperation within groups, particularly in hunter-gatherer bands during 
human evolution, was a competitive advantage. However, many social norms are non-obvious, and "natural selection took advantage of the fact that the cultural transmission pathways of social norms are often the same as those for other more observable markers, like language, dialect, or tattooing practices" (Henrich 2016, 201). Some cultural elements serve humans' coalitional psychology and exist for the sole purpose of signaling group membership and coalitional affiliation (Boyer 2018, 49).

In this view, humans are highly sensitive to sharing observable markers, which they interpret as indicators of sharing the same 'tacit' normative and cultural sub-universe that is crucial for their survival. Paradoxically, humans' inherent tendency toward outgroup hostility is a result of their deeply ingrained sociality. Since we strongly depend on the social-cultural and normative environment constructed by our group, any challenge toward this particular environment would reveal our social vulnerability. The sensitivity toward indicators of difference even became 'wired' in the neural hardware of our social cognition (Greene 2015; Berns and Atran 2012). Therefore, acknowledging culture as a crucial aspect of the human condition implies that cultural differences matter for the history and development of countries (Weber 1972; Rose 2019; Basáñez 2016).

Long before Huntington's work, cultural typologies were common in the field of Business Administration, particularly in the wake of Hofstede's groundbreaking study (Hofstede 1984; Lewis 2018, 121). Recent research based on the World Values Survey reveals cultural differences between countries with respect to values and personality traits (Alexander and Welzel 2011; Norris and Inglehart 2011; Schulz et al. 2019). Western people tend more toward individualism and independence, to impersonal pro-sociality (e.g. trust to strangers), and less toward obedience and conformity (Hofstede 1984; Henrich et al. 2010). In experimental studies on cooperation, Westerners respond more sensitively to sanctions against noncooperation than subjects from Athens, Oman, Russia, or Turkey, for example. The latter tend to regard sanctions as an insult and respond more often with repeated noncooperation (Bowles 2017, 138). From a global comparative perspective, Westerners are Western, educated, industrialized, resourceful, democratic (WEIRD) people and seem to be the exception rather than the rule (Henrich et al. 2010). Research on the WEIRD people supports Weber's notion of the Occident's 
peculiar path. In line with Weber, anthropologists point to the importance of religious institutions and belief systems, but they suggest a different explanation: Westerners became WEIRD in the long run also because the Western Church imposed restrictive marriage policies. The Church "had become obsessed with incest and began to expand the circle of forbidden relatives, eventually including not only distant cousins but also step-relatives, in-laws, and spiritual kin" (Schulz et al. 2019, 2).

Cousin marriages were common in prehistoric societies around the world and resulted in large clans, which provided security for the individual in stateless societies. Communities were characterized by high kinship intensity and clan-like social organization. A clan's reputation determined its power and vulnerability as well as the fate of the individual. In turn, individual behavior represented the reputation of the clan, which is why social control of clan members and women, in particular, became a crucial aspect of clan politics (Weiner 2013, 35). Gellner (1994, 7) described this kind of social order as the "tyranny of cousins". In human history, collectivistic orientations and parochial altruism (Bernhard et al. 2006; Boehm 2011; Bowles 2017) were rather the norm, whereas relevant individualistic WEIRD cultures did not exist. Dissolving clan structures by marriage and family policies of the Western Church (not the Eastern Orthodox Church) cleared the way for the evolution of an individualistic and less conformist culture, where individuals were at the same time more fair and trusting toward strangers. Indeed, the length of exposure to the Western Church correlates positively with indicators of the WEIRD culture, but this exposure obviously differed historically around the world. According to these empirically justified arguments, it can be ascertained that cultural differences still matter today (Schulz et al. 2019; Basáńez 2016).

\section{Cultural Spheres as a Limitation of Isomorphism?}

Sociological neo-institutionalism is in line with the idea that humans live in and strongly depend on self-created social environments (Meyer et al. 1997). Personal identities, goals, and 'individual' decisions are based on narratives needed to develop the self-concept of a person who pursues the 
narrative in a meaningful way. Many of us regard the personal narrative as unique, but such narratives and identities are institutionalized as takenfor-granted options in our social environments (Meyer 2010, 5). In the globalized world society, individuals and organizations are interested in common institutionalized standards when they interact across different national institutions. Due to the activities of international organizations, but also because of its organizational efficiency (Weber 1972), the modern Western-style bureaucracy tends to spread around the world (Meyer et al. 1997). By converging to the Western standard, organizational forms become more and more similar. Meyer's view is therefore in contrast to Huntington's idea of 'fault lines', which are assumed to clearly separate civilizations.

Given the remarkable cultural differences between societies concerning aspects such as gender roles, religious identities, individualism, narratives of ethnic origin, autonomy, or collectivism, the assumed global trend toward transnational isomorphism, in the form and content of education systems, would challenge the maintenance of global cultural diversity. Recently, however, policymakers have become more inclined to draw distinctions related to identity and culture (Fukuyama 2018). One indicator is the rise of right-wing populism in Western democracies; another is the increasing importance of identity politics from a global perspective. If the preservation of culture and identity became more important over the recent decades, we would expect differing cultures in the world to structure the diffusion of education systems, and thereby moderate-accelerate or delay-the isomorphic diffusion of modern education forms and content. If cultural spheres were still relevant today, our empirical study would find at least a moderate effect of cultural clusters on the diffusion of education policy. There might be different pathways to education, even though we expect global diffusion according to the theory of neo-institutionalism.

A crucial question is how to define and measure different global cultures? Inspired by existing cultural typologies, we rely on a set of countries' cultural characteristics, namely, indicators of political liberties, rule of law, gender roles, dominant religion, language group, government ideology, classification of civilization, and colonial past and apply methods 
of two-mode network analysis to generate a fuzzy set typology of what we call 'cultural spheres'.

Figure 1.1 shows a two-mode network approach we use to measure 'cultural spheres'. A two-mode network consists of two different sets of nodes, in our case countries and their cultural characteristics. Countries 1,8 , and 9 share the binary characteristic A, which could be a language group, but 8 and 9 also share $\mathrm{B}$, for example, the same dominant religion, which is why the similarity of 8 and 9 in the country-level projection is higher than, for example, between 1 and 8 (red edge in the right graph). Here, 'projection' means that the two-mode network is transferred into a network of countries, regarding shared characteristics as ties between countries. Since two countries are more similar to each other, the higher is the number of shared ties. The network is thus valued or, synonymously, weighted.

We hypothesize that the focus on the autonomous individual, liberty, fairness, and equity ingrained in the WEIRD culture is not always recognized and accepted as a role model for other cultures in the world (Haidt 2012). Instead of 'assimilating' toward the WEIRD, the issue of identity and identity politics has become increasingly important over the last several decades. In continuation, there might also be explicit defensive actions against isomorphism, particularly in the field of education.
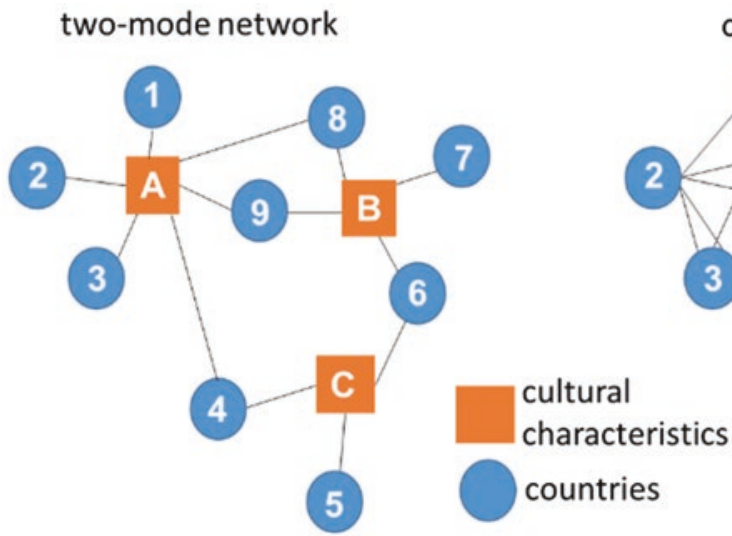

country level projection

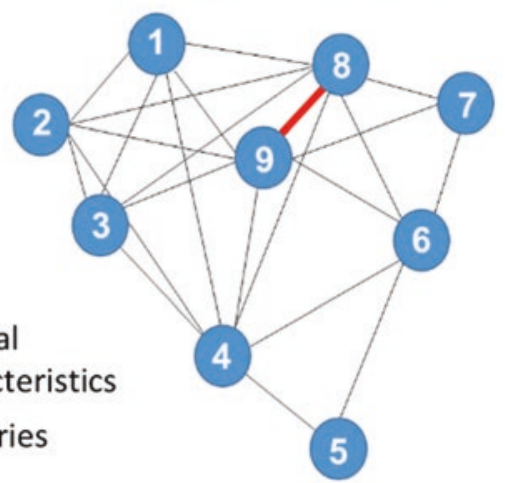

Fig. 1.1 Projection of the two-mode network on the country level 
Education relates closely to a country's cultural heritage as well as its narrative about its history and identity. Therefore, cultural spheres may moderate the diffusion of educations policies in the shape of fuzzy boundaries between different cultural spheres, whereas policies might easily diffuse within a respective sphere.

\section{Horizontal and Vertical Interdependencies Interlinked with National Factors}

In our theoretical framework, culture and cultural spheres are crucial for the diffusion of education policy. Proceeding from the neo-institutionalist hypothesis, the postulated consequence of horizontal and vertical interdependencies would be a global spread of diffusion accompanied by isomorphism. Potential barriers to this diffusion, or decelerators, especially in the field of education, are constituted by national, regional, and culturally specific factors. Resistance, creative enrichment, and new creations can modify the diffusion process or even block it over the course of identity-political defensive reactions. Consequently, educational statehood can follow fully self-contained cultural and regional pathways into modernity. Viewed from a global perspective, the emergence and transformation of education systems depend on horizontal and vertical interdependencies as well as on factors within a given nation-state. Our concept of 'cultural spheres' implies that culture and cultural differences have an impact on the diffusion of education policy. We postulate that cultural-spatial consolidation in networks forms topologies that may counter trends toward global isomorphism in the field of education via horizontal interdependencies.

Some older IOs such as the International Labour Organization (ILO) emphasized the importance of education for social policy to improve quality of life early on and thereby trying to impact upon education policy via vertical interdependencies. The propagated role of education can be investigated in greater detail at the level of the IOs by determining which IOs consider education to be either an important social policy or an important developmental policy in a given country. IOs can universally propagate guiding principles if they can claim global validity. IOs can also pursue 
culturally or regionally specific goals, which means that they concentrate their education policy activities either on a particular region or on a specific cultural group so that they are not transferable to the international community. For instance, the OECD with its Programme for International Student Assessment (PISA) study claims worldwide validity for the 'what works' examples, and in doing so, influences small countries in terms of education policy reform as well as nations that did not take part in the PISA study (Niemann and Martens 2018; Bieber et al. 2014).

However, national factors can mediate horizontal and vertical interdependencies. Economic specialization in the international division of labor and production can also correspond to path-dependent special developments in national education systems, namely, when the economic specialization of a country requires a particular set of competencies in the population (Hidalgo 2015). The same is valid for factors such as the extent of ethnic-cultural diversity or the degree of democratization or autocratization in a country. In contrast to 'classical' social policy, often introduced by some autocratic regimes to close a structural legitimation gap, other autocracies often restrict the expansion of education to maintain the elite's position of power. In both cases, authoritarian regimes use education to reproduce legitimacy (Ansell 2010), which is why the content of state-organized education is also relevant, such as teaching universal ethics, religious instruction, or Marxist-Leninist philosophy in the formerly socialist countries.

One distinctive feature of education as a policy field is that education is intimately entwined with the reproduction of culture and collective identity and as such can function as a set of 'switches', in Max Weber's sense, that determine the course of developmental paths (Knöbl 2007) specific to 'cultural spheres'. In addition to spatial proximity, belonging to world religions, cultural spheres, or particular IOs produces relevant linkages between states that can facilitate a diffusion of education policy. Thus, in many African countries, the influence of Islam on the national education system is evident, similar to the role of zakat in social policy (Richardson 2004). Especially in remote rural regions, the Koran schools ('maktabs') provide the only accessible primary education, while in other regions they compete with the official state primary schools (Brock and Alexiadou 2013, 137). While the 'maktabs' are religious educational 
establishments rather than state schools, the substitutive role they play in certain contexts could counter the adoption and spread of modern Western primary education. Furthermore, the importance of religious education in Central Asia has increased during the post-Soviet period, for instance, in Uzbekistan (Yakhyaeva 2013). Nevertheless, even during the Christian and Islamic colonialization of African countries, the education systems imposed by the colonial powers were being challenged at the level of local communities, mainly by preexisting local cultures, languages, and social structures. However, the diffusion of education policies and innovation may be stronger in other cultural spheres such as Latin America and East Asia.

In sum, our research interests lie in the complex tension between global diffusion (i.e. isomorphism), on the one hand, and subclusters that form in certain regions or 'cultural spheres' and determine particular pathways, mediated by national factors, on the other hand. We investigate the extent to which globally active IOs spread universal ideas about education; how the culturally or regionally specific orientation of IOs limits the global diffusion of education policy; and how it may restrict it to culturally or regionally specific network clusters. Furthermore, we expect culturally specific or regional IOs consolidate the diffusion network within a 'cultural sphere' and thus influence the opportunities for and speed of diffusion. Our hypothesis is that the introduction and configuration of state education correspond to world regions and cultural clusters characterized empirically by consolidated relations and dynamic subnetworks. The focus of our explanation of these patterns lies on territorial and national factors, including culturally shaped objectives and the imperative of maintaining power, urbanization, the growing demand for competencies enabling global economic and technological competition. These factors are mediated by vertical interdependencies, primarily through the programs propagated by IOs for generating human capital. We argue, in addition to the horizontal diffusion processes, IOs - some of which are culture-specific_-also affect national policy fields in a top-down fashion. Thus, the emergence, transformation, and development of education systems can be linked to national factors and the international diffusion of ideas. This diffusion of ideas occurs within a network of relationships that countries participate in and which spreads ideas arising from impulses 
given by IOs. The following questions are considered relevant: Do education systems spread via the cultural spheres network? Which predispositions within countries and which spatial-structural factors affect the likelihood of adopting a characteristic? Consequently, can patterns be found in the diffusion paths of education systems and in the impacts of cultural-specific IOs?

\section{Research Design and Empirical Approach}

For the purposes of this book, we apply a mixed-method approach. We draw on a relational approach to describe cross-national horizontal interdependencies by means of combined network and diffusion analysis and to analyze their policy effects. Although this approach is gaining in popularity (on healthcare policy see Valente 2015), it has rarely been applied to the field of education. In the formation of national education systems and their reform dynamics, including possible turning points, abstract characteristics can diffuse through networks. Examples include high standardization, low stratification, and sufficient resources (Teltemann 2015, 131). Nevertheless, more tangible characteristics of education systems also spread through networks between nation-states, such as compulsory schooling, mass education, and changes in the minimum duration of schooling.

We investigate vertical interdependencies by analyzing the influence of IOs as providers of ideas and impulses for the developmental dynamics of education policy. Previous research on vertical interdependencies showed that the transnational effects generated by internationally operating actors can exert a considerable influence on the transformation of national education policy - at least for the PISA study and the Bologna Process (Martens et al. 2010, 2014). In the PISA study, the OECD highlighted various deficits in national education systems and propagated guiding principles for educational reforms (Bieber et al. 2014). Many of the 80 countries that participated in PISA have initiated reforms of their national education systems based on recommendations of this international comparative study. By means of a systematic qualitative comparison of the programs pursued by IOs that are active in the field of education, we are 
able to more precisely discern the degree of vertical interdependence between education policies.

The research is implemented in three areas of work to explore the transformation of education systems, namely, the compilation of a global data set and the analysis of diffusion processes, networks, and types of education IOs.

\section{Compilation of a Global Data Set on Education Systems}

For the purposes of this work, we compile a global data set incorporating the systems of school education in potentially all countries. The information from these data sets is augmented by the series Education Around the World (Brock and Alexiadou 2013), which describes the education systems of individual countries up until 2013, including their historical dynamics. Historical developmental processes are also described in the International Encyclopedia of National Systems of Education (Postlethwaite 1995) and in greater detail within the volumes of the International Handbook of Education Systems (Cameron 1983). Thus, it is possible to assess the reliability of the data (e.g. on the date when compulsory schooling was introduced) by comparing several sources. Our aim is to systematically classify education reforms and to further develop existing theoretical models of the diffusion, development, and transformation of education systems. The diffusion of information through networks is analyzed using a logistic growth function that portrays the cumulative proportion of "adopters" who have accepted the information (Valente 1995; Rogers 2003). The estimation of the diffusion rate follows a procedure used in event history analysis (Windzio 2013).

\section{The Analysis of Diffusion Processes and International Networks}

In addition to the modifying effect of cultural spheres and world regions, we also consider factors at the level of the nation-state in the analyses of diffusion, such as the Gross Domestic Product (GDP) or levels of 
democratization. A concentration of network contacts in a given cultural sphere does not necessarily imply a simultaneous disintegration of the global network into components between which the individual nodes cannot reach each other. Rather, bridges would arise in the networks (Burt 1992), in this case between cultural spheres. Theoretically, topological structures in the form of "small worlds" (Watts 2004) would be conceivable, with maximal spatial reach of the diffusion being established based on short path distances. These structures arise from a high level of clustering and a low level of random linkages, which means that cliques or highly interconnected "k-plexes" (Newman 2010, 194) can be delineated, which in turn are connected by individual bridges. Spatially or culturally consolidated clusters can therefore produce "small world" networks at the global level.

Recent research on diffusion through networks shows that specific network topologies (such as a random network with overall short path distances or highly consolidated subclusters) considerably influence the likelihood that information is diffused. If, on the one hand, we take the case of innovations that are only adopted after sustained confirmation through repeated contacts, short average path distances promote diffusion. On the other hand, the number of overlapping group memberships is also relevant (Centola 2015); if, for example, countries are part of a specific cultural sphere and members of certain IOs where the IO memberships open redundant bridges to other cultural spheres. We expect that the strength of a given cultural sphere's influence is relative to the influence of universalistic intercontinental IOs (e.g. United Nations Educational, Scientific and Cultural Organization (UNESCO)). These IOs can determine whether there is either a trend toward the global spread of Western-style education systems, as expected by neo-institutionalism, or whether systematic regional and cultural differences between education systems continue to exist, due to autonomous paths and other factors.

We expect that the introduction and spread of new organizational forms in the education sector at the global level proceed according to a diffusion model. For example, Wollons (2000) proves this idea with the example of the kindergarten, developed around 1850 by the German pedagogue Friedrich Froebel. Froebel trained teachers in Berlin, who then spread the idea to other countries, including the United States. 
Japanese teachers imported it to Japan and from there it spread to China so that only 60 years later, "kindergartens were everywhere, including Africa and Asia, where colonial powers and missionaries introduced kindergartens to modernize local people" (Rogers 2003, 63). Since the education sector is closely interwoven with the cultural uniqueness of a given nation-state, creative new ideas and practices emerged during diffusion. Thus, Froebel's original socialist idea was modified and 'recontextualized' (Wollons 2000).

This example demonstrates the linkages between nation-states that facilitate diffusion can be present at several levels. Specialized actors enter into transnational contact, especially in cases where nation-states are actively searching for role models for their facilities or the transformation of their education systems. Even countries that were not involved in long-term colonial dependencies, such as China or Japan, actively sought exchange with European or North American education experts (Brock and Alexiadou 2013, 8). In addition to intentional contact between experts, nation-states are interconnected through close economic relations and membership in IOs, including in the fields of education and culture. As recent studies on diffusion and the transfer of policies have shown, the geographical proximity between nation-states can lead to mutual influence via various mechanisms (Obinger et al. 2013). Furthermore, networks of converging interests between countries may be formed based on their tendencies toward similar voting behavior in the United Nations (UN) (e.g. Voeten 2000). The analytical representation of the networks between countries can also be based on a combination of these characteristics. Thus, countries can be connected by their shared history under the same colonial power, even though they would otherwise not be connected because they are located in different cultural spheres or world regions.

\section{Leitmotifs and Typology of International Education Organizations}

In our work, we also analyze the guiding principles for education propagated by IOs and how linkages between education-focused IOs are constituted. Building upon earlier works of Bremen education policy 
researchers (Nagel et al. 2010) we distinguish between two ideal types of education policy leitmotifs. Leitmotifs are understood here as a recurring conceptualized theme of the purpose of education. They are composed of ideas that establish (ontological) links between causes and effects (Goldstein and Keohane 1993). On the one hand, education's economic utility can be emphasized through a leitmotif. In this view, the formation of human capital and economic productivity is prevalent. On the other hand, education policy is a means to raise humanistic liberal citizens. In this view, the generation of responsible citizens and their ability for political and social participation is the focus. These types are not mutually exclusive; rather, they reflect the broad values education can have. Moreover, both perspectives on education can be applied to the individual level as well as to the collective or national level (Table 1.1).

Overall, 30 IOs have been revealed as being active in education policy (Niemann and Martens 2021). Of these, we select six organizations for detailed analysis. On the one hand, we look at three education IOs with the word 'education' in their names: UNESCO, Islamic World Education, Science and Culture Organization (ICESCO), and the Southeast Asian Ministers of Education Organization (SEAMEO). We refer to these as the dedicated education organizations. We expect these IOs to represent interests specific to education and orient their guiding principles less toward producing human capital. For UNESCO, the universalist principle of 'education as a human right' is in the foreground, whereas ICESCO and SEAMEO appear to propagate more culturally particularistic values. Second, the three leading IOs active in the fields of economics and labor, which also concern themselves with the education sector among their other range of tasks, are selected. We refer to these as

Table 1.1 Spectrum of education leitmotifs

\begin{tabular}{|c|c|c|}
\hline & Economic utilitarianism & Humanistic liberal citizenship \\
\hline $\begin{array}{l}\text { Individual } \\
\text { level }\end{array}$ & $\begin{array}{l}\text { Skill formation: Focus on } \\
\text { education as improving } \\
\text { individual productivity }\end{array}$ & $\begin{array}{l}\text { Self-fulfillment: Focus on } \\
\text { education as a means for } \\
\text { personal self-development }\end{array}$ \\
\hline $\begin{array}{l}\text { Collective } \\
\text { level }\end{array}$ & $\begin{array}{l}\text { Wealth of nations: Focus on } \\
\text { education as boosting } \\
\text { national economic growth }\end{array}$ & $\begin{array}{l}\text { Social right and duty: Focus on } \\
\text { education to ensure political } \\
\text { and social participation }\end{array}$ \\
\hline
\end{tabular}

Source: Adapted from Nagel et al. (2010: 16), own account 
derivative education organizations as they incorporated education into their activities under an economistic perception: the OECD, the WB, and the ILO. While the OECD represents the 'advanced economies', the WB provides loans to the Global South. The ILO is the worldwide operating special agency of the UN concerned with labor and tasked with promoting social justice as well as human and workers' rights. We assume these economically oriented organizations primarily take a human capital approach in their guiding principles for education. This selection also means that, on the one hand, three UN special agencies (WB, ILO, and UNESCO) form part of our sample. In these organizations all recognized states can become members. On the other hand, three IOs in our sample impose specific membership criteria, namely, a high level of economic development (OECD), religious affiliation (ICESCO), and geographical position (SEAMEO). Based on documents and expert interviews, the IOs' guiding principles and the modes of their diffusion over time are described, as well as the influence of other IOs (Table 1.2).

Our investigation also focuses on analyzing the centrality of the IOs as well as contextualizing them within the broader network of IOs. Research questions include: Which other IOs does the IO in question have close relationships to? If close relationships are present, are the guiding principles for education similar across the IOs involved? Biermann (2008) thus proposes three cooperative mechanisms for forming network relationships, namely, exchange of information, coordination of activities, and shared decision-making. Meanwhile, in the Yearbook of International Organizations (https://uia.org/yearbook), membership of an IO in the

Table 1.2 Typology of the education IOs

\begin{tabular}{|c|c|c|}
\hline Responsibility & $\begin{array}{l}\text { Derivative education } \\
\text { organizations }\end{array}$ & $\begin{array}{l}\text { Dedicated education } \\
\text { organizations }\end{array}$ \\
\hline \multicolumn{3}{|l|}{ Open to any state } \\
\hline Focus: Labor & ILO & \\
\hline Focus: Education/culture & & UNESCO \\
\hline $\begin{array}{l}\text { Focus: Development } \\
\text { Restricted by specific criteria }\end{array}$ & World Bank & \\
\hline Focus: Economic development & OECD & \\
\hline Focus: Religion & & ICESCO \\
\hline Focus: Geographical position & & SEAMEO \\
\hline
\end{tabular}


boards of other IOs, consultations between IOs, or even just mutual citations are recorded. With this data, network analyses can be conducted to calculate the local extent of centrality (i.e. as characteristics of the nodes in the network, e.g. "closeness centrality" or "betweenness centrality"; Wasserman and Faust 1994), and these results can be used to measure the structural prerequisites for the influence of one IO on other IOs. Nonetheless, such a network analysis is predominantly heuristic; we can investigate the question of what IOs in central network positions actually do, and if they exert a hegemonic influence, only by employing qualitative analysis in a second step.

Therefore, this work aims to analyze the diffusion processes and to investigate the linkages between IOs and the guiding principles they propagate, which yield an overview of global activities; in addition, the intensity and degree of vertical interdependencies in the field of education are explored. Furthermore, the adherence of national education systems to the propagated guiding principles are investigated for either the respective cultural sphere or for possible network subclusters.

\section{Structure of the Book}

While this introduction provides the theoretical and analytical framework for the volume, eight substantial chapters examine the global development, diffusion, and transformation of education policies empirically. The volume ends with a commentary and a conclusion.

In Chap. 2, Helen Seitzer, Fabian Besche-Truthe, and Michael Windzio investigate the diffusion of compulsory education from a global perspective. Compulsory education closely relates to the reproduction and change of a country's culture, while possibly facilitating the process of modernization. In this chapter, the authors analyze the diffusion of compulsory education by focusing on the effect of a country's membership in different clusters defined by cultural characteristics. Global cultural clusters of countries do not necessarily have rigid, clear-cut boundaries or 'fault lines' but are fuzzy sets. Thus, the authors apply valued two-mode social network analysis to define global 'cultural spheres'. Following this approach, countries are tied to each other by sharing cultural 
characteristics, but the resulting 'cultural spheres' have fuzzy boundaries: Countries become more connected to each other the more cultural characteristics they share. The resulting network is the structural framework behind the social network diffusion process of compulsory education. The impact of cultural spheres on the diffusion process, controlling for indicators of economic development, is tested by exposure in terms of close cultural ties to other countries with compulsory education, where they are found to significantly increase the rate of adoption.

In Chap. 3, Fabian Besche-Truthe looks at the global trajectories of compulsory education. There exists a plethora of studies that examine fundamental policy changes at the national level from a transnational or global perspective. Such studies have highlighted, for example, the worldwide introduction of mass schooling in the nineteenth and twentieth centuries (Meyer et al. 1997), and the universal spread of compulsory education, which started with 12 early adopters in 1850 and has now been introduced by 162 countries in 2018 (Besche-Truthe et al. 2020, 2021). In comparison, the global policy trend of expanding the duration of compulsory education has been less explored. Besche-Truthe draws on the concepts of trajectories and "pathways" (Verger et al. 2016) to surface the various development paths that account for the adoption of this particular global education policy, resulting in the worldwide extension of compulsory education. A sequence analysis (SQA) lends itself as a method of inquiry because it enables the researcher to regard the whole trajectory of policy development as a single unit of analysis. Recent developments in methodology have opened new gateways in using SQA within the social sciences. The chapter yields an exploration into different trajectories as well as into which national socioeconomic and cultural constellations best explain these specific development paths.

In Chap. 4, Helen Seitzer and Michael Windzio address PISA scores, student exchange, and (family) migration. PISA, a triennial study on education system effectiveness starting in 2000, has led to the very public discussion and comparison of countries' education systems. The study's results are used to name and shame the 'best' and 'worst' of state education. This led to a surge of education policy reforms and directed the general public's attention to education. Better education and job prospects are some of the reasons for migration patterns. They might also 
influence students' choice of the destination country for exchange programs. However, there are no studies combining a network approach to migration, student exchange, and the coevolution of PISA scores. Seitzer and Windzio, therefore, ask if a country's education system reputation coincides with student exchange flows and family migration patterns, or if other factors such as cultural similarity are the reason for choosing a destination?

In Chap. 5, Dennis Niemann reviews IOs and their new interpretations on old education paradigms. Different ideological paradigms have dominated the global education discourse at different periods. Fundamentally, they revolve around the two poles of an economic utilitarian view on education and on an interpretation that emphasizes the cultural value of education in enabling refined citizens. Both paradigmatic leitmotifs were influenced by general developments in world politics, and they were also reflected in international organizations. In this chapter, Niemann analyzes how major education IOs, namely, the WB, UNESCO, the ILO, and the OECD, influenced the global discourse on education and how they interacted with each other. First, he argues that within the IOs, the two antipodal views on education (neoliberalism vs. citizenship) became more complementary over time. Second, he shows that the pattern of interaction between the four IOs has also changed from competition to cooperation.

In Chap. 6, Helen Seitzer analyzes OECD reports regarding the education topics they address. Through its country reports, extensive data collection on the effectiveness of education systems, and policy advice, the OECD is contributing considerably to the diffusion of a transnational model of education. However, critics argue, one size does not fit all, and policy advice distributed in a watering can system is not helping countries to advance their education systems due to their specific local conditions. In this chapter, Seitzer uses a topic model to determine whether the OECD does in fact discuss the same issues in its country reports on education with all countries, or if there are local clusters to be found and thus reports are tailored to the local condition. Seitzer finds regional clusters due to similarity in economic and cultural conditions.

In Chap. 7, David Krogmann looks at IOs and education in the Islamic World. There are a number of education IOs of predominantly Muslim 
member states that have not yet been reviewed systematically in the almost 40 years of their existence. This chapter maps the existing education IOs in the Muslim world. The analysis presented here revolves around two main questions: First, which organizations with predominantly Muslim member states are active in the field of international education policy, and how, if at all, do they cooperate with each other? Second, which education leitmotifs do these organizations promote, and what kind of discourse do they construct around education policy? The analysis finds Muslim education IOs, namely, the ICESCO, Arab Bureau of Education for the Gulf States (ABEGS), and Arab League Cultural, Educational and Scientific Organization (ALECSO), participate in a distinct discourse that revolves around the synthesis of traditional values drawn from Islamic philosophy and the demands of a modern global labor market.

In Chap. 8, regional identities in international education organizations are the focus of attention in David Krogmann's chapter on SEAMEO. SEAMEO has been a major player in education policy in Southeast Asia for decades. Despite its history, it has not garnered attention by scholars of international education. This chapter represents a first step toward filling the gap by exploring the underlying themes and ideas that inform discursive patterns produced and reproduced by SEAMEO. How does SEAMEO conceive of education? Did SEAMEO's image of education evolve over time? The analysis by Krogmann finds SEAMEO mostly follows the UN's global sustainable development agenda in education policy, stressing both the social as well as the economic purposes of education. Nevertheless, it does so with a distinct emphasis on the educational purpose of reinforcing the collectively shared values and traditions of its member states, which it deems unique to Southeast Asia.

In Chap. 9, Michael Windzio and Raphael Heiberger examine which topics are important for major education IOs. IOs in the field of education follow different ideological paradigms in the global education discourse. According to our theoretical concept, we distinguish between dedicated and derivative IOs. Derivative IOs in the field of education mainly focus on other important issues, such as economic prosperity or economic development in the Global South. In contrast, dedicated IOs 
focus on education policy as their major issue. Yet, it is an open question as to whether these different types of IOs also focus on different topics and thereby support different paradigms of education. Based on more than 1000 documents published by the WB, UNESCO, the ILO, the OECD, ICESCO, and SEAMEO, they explore education issues as dealt with in this sample. Using standardized methods of qualitative text analysis, in particular topic modeling, Heiberger, Seitzer, and Windzio explore whether the major topics found in these documents do indeed differ between the different types of organizations or not.

In Chap. 10, John W. Meyer contributes a commentary to the book in light of his long-standing work within the sociology of education from a neo-institutionalist perspective. The concluding Chap. 11 by Michael Windzio and Kerstin Martens, evaluates the theoretical framework presented in this Introduction in light of the empirical findings of the individual chapters. The chapter also points out avenues for further research resulting from this volume.

\section{References}

Alexander, Amy C., and Christian Welzel. 2011. Islam and Patriarchy: How Robust Is Muslim Support for Patriarchal Values? World Values Research 4 (2): 40-70.

Allais, Stephanie. 2012. 'Economics Imperialism': Education Policy and Educational Theory. Journal of Education Policy 27 (2): 253-274. https://doi. org/10.1080/02680939.2011.602428.

Allmendinger, Jutta, and Stephan Leibfried. 2003. Education and the Welfare

State: The Four Worlds of Competence Production. Journal of European Social Policy 13 (1): 63-81.

Ansell, Ben W. 2010. From the Ballot to the Blackboard. The Redistributive

Political Economy of Education. New York: Cambridge University.

Ansell, Ben W., and Johannes Lindvall. 2013. The Political Origins of Primary Education Systems: Ideology, Institutions, and Interdenominational Conflict in an Era of Nation-Building. American Political Science Review 107 (3): $505-522$. 
Barro, Robert, and Jong-Wha Lee. 2013. A New Data Set of Educational Attainment in the World, 1950-2010. Journal of Development Economics 104: 184-198.

Basáñez, Miguel E. 2016. A World of Three Cultures: Honor, Achievement and Joy. Oxford: Oxford University Press.

Benavot, Aaron, and Phyllis Riddle. 1988. The Expansion of Primary Education, 1870-1940: Trends and Issues. Sociology of Education 61 (3): 191-210.

Bernhard, Helen, Urs Fischbacher, and Ernst Fehr. 2006. Parochial Altruism in Humans. Nature 442 (7105): 912-915. https://doi.org/10.1038/ nature04981.

Berns, Gregory S., and Scott Atran. 2012. The Biology of Cultural Conflict. Philosophical Transactions: Biological Sciences 367 (1589): 633-639.

Besche-Truthe, Fabian, Helen Seitzer, and Michael Windzio. 2020. Cultural Spheres_Creating a Dyadic Dataset of Cultural Proximity. SFB 1342 Technical Paper Series 5.

— 2021, forthcoming. Global 'Cultural Spheres' and the Introduction of Compulsory Schooling around the World. In Impacts on Social Policy: Short Histories in a Global Perspective, ed. Frank Nullmeier, Delia González de Reufels, and Herbert Obinger. Cham: Palgrave Macmillan.

Bieber, Tonia, and Kerstin Martens. 2011. The OECD PISA Study as a Soft Power in Education? Lessons from Switzerland and the US. European Journal of Education 46 (1): 101-116.

Bieber, Tonia, Kerstin Martens, Dennis Niemann, and Michael Windzio. 2014. Grenzenlose Bildungspolitik? Empirische Evidenz für PISA als weltweites Leitbild für nationale Bildungsreformen. Zeitschrift für Erziehungswissenschaft 14: 141-166.

Biermann, Rafael. 2008. Towards a Theory of Inter-Organizational Networking. The Review of International Organizations 3 (2): 151-177.

Boehm, Christopher. 2011. Moral Origins: Social Selection and the Evolution of Virtue and Shame. New York: Basic Books.

Boli, John, Francisco Ramirez, and John W. Meyer. 1985. Explaining the Origins and Expansion of Mass Education. Comparative Education Review 29 (2): $145-170$.

Bowles, Samuel. 2017. The Moral Economy: Why good Incentives are No Substitute for Good Citizens. New Haven: Yale University Press.

Boyer, Pascal. 2018. Minds Make Societies. How Cognition Explains the World Humans Create. New Haven: Yale University Press. 
Brock, Colin, and Nafiska Alexiadou. 2013. Education Around the World: A Comparative Introduction. London: Bloomsbury.

Burt, Ronald S. 1992. Structural Holes: The Social Structure of Competition. Cambridge: Cambridge University Press.

Busemeyer, Marius R., and Christine Trampusch. 2011. Comparative Political Science and the Study of Education. British Journal of Political Science 41 (2): 413-443.

Cameron, John, ed. 1983. International Handbook of Education Systems. Chichester: Wiley.

Castles, Stephen, Hein de Haas, and Mark J. Miller. 2014. The Age of Migration: International Population Movements in the Modern World. 5th ed. Basingstoke: Palgrave Macmillan.

Centola, Damon. 2015. The Social Origins of Networks and Diffusion. American Journal of Sociology 120 (5): 1295-1338.

Cummings, Stephen, Todd Bridgman, John Hassard, and Michael Rowlinson. 2017. A New History of Management. Cambridge: Cambridge University Press. Eisenstadt, Shmuel N. 1986. The Axial Age Breakthroughs - Their Characteristics and Origins. In The Origins and Diversity of Axial Age Civilizations, ed. Shmuel N. Eisenstadt, 1-29. Albany: State University of New York Press.

Emirbayer, Mustafa. 1997. Manifesto for a Relational Sociology. American Journal of Sociology 103 (2): 281-317. https://doi.org/10.1086/231209.

Emirbayer, Mustafa, and Jeff Goodwin. 1994. Network Analysis, Culture, and the Problem of Agency. American Journal of Sociology 99 (6): 1411-1454.

Finnemore, Martha. 1993. International Organizations as Teachers of Norms: The United Nations Educational, Scientific, and Cultural Organization and Science Policy. International Organization 47 (4): 565-597.

1996. Norms, Culture, and World Politics: Insights from Sociology's Institutionalism. International Organization 26 (2): 325-347.

Fukuyama, Francis. 1992. The End of History and the Last Man. New York: Free Press.

- 2018. Identity. The Demand for Dignity and the Politics of Resentment. New York: Farrar, Straus and Giroux.

Gellner, Ernest. 1994. Conditions of Liberty-Civil Society and Its Rivals. London: Hamilton.

Gift, Thomas, and Erik Webbel. 2014. Reading, Writing, and the Regrettable Status of Education Research in Comparative Politics. Annual Review of Political Science 17 (1): 291-312. 
Goldstein, Judith, and Robert O. Keohane, eds. 1993. Ideas and Foreign Policy: Beliefs, Institutions, and Political Change. Cornell: Cornell University Press.

Green, Andy. 2013. Education and State Formation: Europe, East Asia and the USA. 2nd ed. Basingstoke: Palgrave Macmillan.

Greene, Joshua D. 2015. Moral Tribes. Emotion, Reason, and the Gap between Us and Them. London: Atlantic Books.

Grek, Sotiria. 2010. International Organisations and the Shared Construction of Policy 'Problems': Problematisation and Change in Education Governance in Europe. European Educational Research Journal 9 (3): 396-406.

Haidt, Jonathan. 2012. The Righteous Mind: Why Good People are Divided by Politics and Religion. London: Allen Lane.

Hanushek, Eric A., Paul E. Peterson, and Ludger Woessmann. 2013. Endangering Prosperity: A Global View of the American School. Washington, DC: The Brookings Institution Press.

Henrich, Joseph P. 2016. The Secret of our Success. How Culture is Driving Human Evolution, Domesticating our Species, and Making Us Smarter. Princeton: Princeton University Press.

Henrich, Joseph P., Steven Heine, and Ara Norenzayan. 2010. The Weirdest People in the World? The Behavioral and Brain Sciences 33 (2-3): 61-83.

Hidalgo, César A. 2015. Why Information Grows: The Evolution of Order, from Atoms to Economies. London: Allen Lane.

Hofstede, Geert. 1984. Culture's Consequences: International Differences in WorkRelated Values. Newbury Park: Sage.

Huntington, Samuel P. 1993. The Clash of Civilizations? Foreign Affairs 72 (3): 22-49.

-1996. The Clash of Civilizations and the Remaking of World Order. New York: Simon \& Schuster.

Jakobi, Anja P., and Janna Teltemann. 2011. Convergence in Education Policy? A Quantitative Analysis of Policy Change and Stability in OECD Countries. Compare: A Journal of Comparative and International Education 51 (5): 579-595.

Jakobi, Anja P., Kerstin Martens, and Klaus Dieter Wolf, eds. 2010. Education in Political Science. Discovering a Neglected Field. London: Routledge.

Karseth, Berit, Kirsten Sivesind, and Gita Steiner-Khamsi, eds. 2021. Evidence and Expertise in Nordic Education Policies: A Comparative Network Analysis from the Nordic Region. Cham: Palgrave Macmillan.

Knöbl, Wolfgang. 2007. Die Kontingenz der Moderne: Wege in Europa, Asien und Amerika. Frankfurt a.M.: Campus. 
Krücken, Georg. 2005. Der world-polity-Ansatz in der Globalisierungsdiskussion. In Weltkultur: Wie die westlichen Prinzipien die Welt durchdringen, ed. John W. Meyer and Georg Krücken, 300-318. Frankfurt a.M.: Suhrkamp.

Lewis, Richard D. 2018. When Cultures Collide. Leading Across Cultures. 4th ed. London: Nicholas Brealey Publishing.

Maoz, Zeev. 2011. Networks of Nations: The Evolution, Structure, and Impact of International Networks, 1816-2001. Cambridge: Cambridge University Press. Marshall, Thomas H. 1964 [1949]. Citizenship and Social Class. In Class, Citizenship, and Social Development: Essays, ed. Thomas H. Marshall, 65-122. Garden City, NY: Doubleday.

Martens, Kerstin, Alexandra Rusconi, and Kathrin Leuze, eds. 2007. New Arenas of Education Governance: The Impact of International Organizations and Markets on Educational Policy Making. Basingstoke: Palgrave Macmillan.

Martens, Kerstin, Alexander-Kenneth Nagel, Michael Windzio, and Ansgar Weymann, eds. 2010. Transformation of Education Policy. Basingstoke: Palgrave Macmillan.

Martens, Kerstin, Philipp Knodel, and Michael Windzio, eds. 2014. Internationalization of Education Policy: A New Constellation of Statehood in Education? Basingstoke: Palgrave Macmillan.

McNeely, Connie L., and Yun-Kyung Cha. 1994. Worldwide Educational Convergence through International Organizations: Avenues for Research. Education Policy Analysis Archives 2 (14). https://doi.org/10.14507/epaa. v2n14.1994.

Meyer, John W. 1977. The Effects of Education as an Institution. American Journal of Sociology 83 (1): 55-77.

2010. World Society, Institutional Theories, and the Actor. Annual Review of Sociology 36 (1): 1-20. https://doi.org/10.1146/annurev. soc.012809.102506.

Meyer, John W., Francisco O. Ramirez, and Yasemin N. Soysal. 1992. World Expansion of Mass Education, 1870-1980. Sociology of Education 65 (2): 128-149.

Meyer, John W., John Boli, George Thomas, and Francisco O. Ramirez. 1997. World Society and the Nation-State. American Journal of Sociology 103 (1): 144-181.

Mundy, Karen. 2007. Educational Multilaterism-Origins and Indicators for Global Governance. In New Arenas of Education Governance: The Impact of International Organizations and Markets on Educational Policy Making, ed. 
Kerstin Martens, Alessandra Rusconi, and Kathrin Leuze, 19-38. Basingstoke: Palgrave Macmillan.

Mundy, Karen, and Antoni Verger. 2015. The World Bank and the Global Governance of Education in a Changing World Order. International Journal of Educational Development 40 (1): 9-18. https://doi.org/10.1016/j. ijedudev.2014.11.021.

Nagel, Alexander-Kenneth, Kerstin Martens, and Michael Windzio. 2010. Introduction-Education Policy in Transformation. In Transformation of Education Policy, ed. Kerstin Martens, Alexander-Kenneth Nagel, Michael Windzio, and Ansgar Weymann, 3-28. Basingstoke: Palgrave Macmillan.

Newman, Mark E. 2010. Networks: An Introduction. Oxford: Oxford University Press.

Niemann, Dennis, and Kerstin Martens. 2018. Soft Governance by Hard Facts? The OECD as a Knowledge Broker in Global Education Policy. Global Social Policy 18 (3): 267-283. https://doi.org/10.1177/1468018118794076.

2. 2021. Global Discourses, Regional Framings and Individual Showcasing: Analyzing the World of Education IOs. In International Organizations in Global Social Governance, ed. Kerstin Martens, Alexandra Kaasch, and Dennis Niemann, 163-186. Cham: Palgrave Macmillan.

Norris, Pippa, and Ronald Inglehart. 2011. Sacred and Secular. Religion and Politics Worldwide. 2nd ed. Cambridge: Cambridge University Press.

Obinger, Herbert, Carina Schmitt, and Peter Starke. 2013. Policy Diffusion and Policy Transfer in Comparative Welfare State Research. Social Policy \& Administration 47 (1): 111-129.

Perry, Glenn E. 2002. Huntington and His Critics: The West and Islam. Arab Studies Quarterly 24 (1): 31-48.

Postlethwaite, T. Neville, ed. 1995. International Encyclopedia of National Systems of Education. Oxford: Pergamon.

Richardson, Gail. 2004. Islamic Law and Zakat: Waqf Resources in Pakistan. In Islam and Social Policy, ed. Stephen P. Heyneman, 156-180. Nashville, TN: Vanderbilt University Press.

Rogers, Everett M. 2003. Diffusion of Innovations. New York: The Free Press. Rose, David C. 2019. Why Culture Matters Most. Oxford: Oxford University Press. Schulz, Jonathan F., Duman Bahrami-Rad, Jonathan P. Beauchamp, and Joseph Henrich. 2019. The Church, Intensive Kinship, and Global Psychological Variation. Science 366 (6466). https://doi.org/10.1126/science.aau5141.

Teltemann, Janna. 2015. Ungleichheit als System? Der Schulerfolg von Migranten im internationalen Vergleich. Frankfurt a.M.: Campus. 
Teltemann, Janna, and Michael Windzio. 2011. Die 'kognitive Exklusion' junger Migranten im Ländervergleich: Effekte institutioneller und sozialstruktureller Faktoren. Berliner Journal für Soziologie 21 (3): 335-361.

2019. The Impact of Marketisation and Spatial Proximity on Reading Performance: International Results from PISA 2012. Compare 49 (5): 777-794. https://doi.org/10.1080/03057925.2018.1458597.

Valente, Thomas W. 1995. Network Models of the Diffusion of Innovations. Cresskill: Hampton Press.

- 2015. Diffusion of Innovations Theory Applied to Global Tobacco Control Treaty Ratification. Social Science \& Medicine 145: 89-97.

Verger, Antoni. 2012. Framing and Selling Global Education Policy: The Promotion of Public-Private Partnerships for Education in Low-Income Contexts. Journal of Education Policy 27 (1): 109-130.

Verger, Antoni, Clara Fontdevila, and Adrian Zancajo. 2016. The Privatization of Education: A Political Economy of Global Education Reform. New York, NY: Teachers College Press.

Voeten, Erik. 2000. Clashes in the Assembly. International Organization 54 (2): $185-215$.

Vögtle, Eva Maria, and Michael Windzio. 2019. Looking for Freedom? Networks of International Student Mobility and Countries' Levels of Democracy. The Geographical Journal 186 (1): 103-115. https://doi.org/10.1111/geoj.12329. Wasserman, Stanley, and Katherine Faust. 1994. Social Network Analysis: Methods and Applications. Cambridge: Cambridge University Press.

Watts, Duncan J. 2004. The 'New' Science of Networks. Annual Review of Sociology 30: 243-270. https://doi.org/10.1146/annurev.soc.30.020404.104342.

Weber, Max. 1972. Wirtschaft und Gesellschaft: Grundriß der verstehenden Soziologie. Tübingen: Mohr.

Weiner, Mark Stuart. 2013. The Rule of the Clan. What an Ancient Form of Social Organization Reveals about the Future of Individual Freedom. New York: Farrar, Straus and Giroux.

Weymann, Ansgar. 2014. States, Markets and Education: The Rise and Limits of the Education State. Basingstoke: Palgrave Macmillan.

Windzio, Michael. 2013. Integration and Inequality in Educational Institutions: An Institutional Perspective. In Integration and Inequality in Educational Institutions, ed. Michael Windzio, 3-20. Dordrecht: Springer.

. 2018. The Network of Global Migration 1990-2013: Using ERGMs to Test Theories of Migration between Countries. Social Networks 53: 20-29. https://doi.org/10.1016/j.socnet.2017.08.006. 
Windzio, Michael, Céline Teney, and Sven Lenkewitz. 2019. A Network Analysis of Intra-EU Migration Flows. How Regulatory Policies, Economic Inequalities and the Network-Topology Shape the Intra-EU Migration Space. Journal of Ethnic and Migration Studies 45: 1-19. https://doi.org/10.108 0/1369183X.2019.1643229.

Wolf, Frieder, and Reimut Zohlnhöfer. 2009. Investing in Human Capital? The Determinants of Private Education Expenditure in 26 OECD Countries. Journal of European Social Policy 19 (3): 230-244.

Wollons, Roberta Lyn. 2000. On the International Diffusion, Politics, and Transformation of the Kindergarten. In Kindergartens and Cultures: The Global Diffusion of an Idea, ed. Roberta Lyn Wollons, 1-15. New Haven, CN: Yale University Press.

Yakhyaeva, Laliya. 2013. Uzbekistan: An Overview. In Education in West Central Asia, ed. Mah-E-Rukh Ahmed, 289-310. London: Bloomsbury.

Ydesen, Christian, ed. 2019. The OECD's Historical Rise in Education: The Formation of a Global Governing Complex. Cham: Palgrave Macmillan.

Open Access This chapter is licensed under the terms of the Creative Commons Attribution 4.0 International License (http://creativecommons.org/licenses/ by/4.0/), which permits use, sharing, adaptation, distribution and reproduction in any medium or format, as long as you give appropriate credit to the original author(s) and the source, provide a link to the Creative Commons licence and indicate if changes were made.

The images or other third party material in this chapter are included in the chapter's Creative Commons licence, unless indicated otherwise in a credit line to the material. If material is not included in the chapter's Creative Commons licence and your intended use is not permitted by statutory regulation or exceeds the permitted use, you will need to obtain permission directly from the copyright holder.

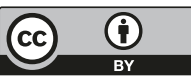

